\title{
Association between maternal age and adverse perinatal outcomes in Arba Minch zuria, and Gacho Baba district, southern Ethiopia: a prospective cohort study
}

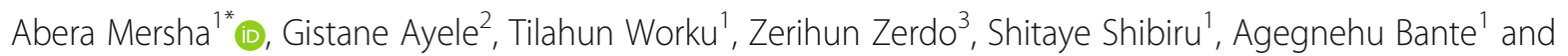
Tamiru Chonka'

\begin{abstract}
Background: Globally, delayed childbearing to the advanced age is a growing option. It is an emerging public health issue in developing countries. Currently, adverse perinatal outcomes significantly increased. A few studies showed the effect of advanced maternal age on adverse perinatal outcomes. However, most used secondary data or chart reviews, and this increases the risk of biases. Besides, there are limited studies in-country Ethiopia as advanced maternal age steadily increased. Therefore, this study aimed to assess the status of advanced maternal age and its effect on perinatal outcomes in the study setting.

Methods: A community-based prospective cohort study was conducted among 709 study participants from October 15, 2018, to September 30, 2019, in Arba Minch zuria, and Gacho Baba district, southern Ethiopia. The data were collected by a pretested interviewer-administered structured Open Data Kit survey tool and analyzed by SPSS version 25. The log-linear regression model was used to compare perinatal outcomes among women aged 20-34 years and $\geq 35$ years. The log-likelihood ratio tested for the goodness of fit. In this study, $P$-value $<0.05$ was considered to declare a result as a statistically significant association.

Results: In this study, 209(29.5\%) of the women were age group $\geq 35$ years old, and 500(70.5\%) were age group from 20-34 years old. Stillbirth ( $\beta=0.29,95 \% \mathrm{Cl}$ : $0.05,0.52$ ), and neonatal mortality ( $\beta=0.11,95 \% \mathrm{Cl}$ : $0.01,0.21$ ) were significantly associated with the advanced maternal age.

Conclusions: Perinatal outcomes such as stillbirth and neonatal mortality were independently associated with advanced maternal age after controlling for possible cofounders. Therefore, different strategies should design for the women who planned to bear child, and information should provide for women who are advanced age or delayed childbearing to alert them.
\end{abstract}

Keywords: Advanced maternal age, Perinatal outcomes, Arba Minch

\footnotetext{
* Correspondence: mershaabera@gmail.com

${ }^{1}$ School of Nursing, College of Medicine and Health Sciences, Arba Minch University, Arba Minch, Ethiopia

Full list of author information is available at the end of the article
}

C C The Author(s). 2020 Open Access This article is licensed under a Creative Commons Attribution 4.0 International License, which permits use, sharing, adaptation, distribution and reproduction in any medium or format, as long as you give appropriate credit to the original author(s) and the source, provide a link to the Creative Commons licence, and indicate if changes were made. The images or other third party material in this article are included in the article's Creative Commons licence, unless indicated otherwise in a credit line to the material. If material is not included in the article's Creative Commons licence and your intended use is not permitted by statutory regulation or exceeds the permitted use, you will need to obtain permission directly from the copyright holder. To view a copy of this licence, visit http://creativecommons.org/licenses/by/4.0/. The Creative Commons Public Domain Dedication waiver (http://creativecommons.org/publicdomain/zero/1.0/) applies to the data made available in this article, unless otherwise stated in a credit line to the data. 


\section{Background}

Advanced maternal age, the reason, and its consequences in a global context, and in Africa

Advanced maternal age (AMA) means the age group of 35 years or older [1-3]. Worldwide, delayed childbearing is a growing option [4-6]. The prevalence of pregnant women with AMA was $12.3 \%$ in the study conducted in 359 health facilities of 29 countries in Africa, Asia, Latin America, and the Middle East [7]. A study from Israel showed $45.7 \%$ of women were AMA, $33.4 \%$ in the study from Norway, and $14.8 \%$ in the report from Malaysia [8-10].

Belated marriage, a higher level of education, career pursuit, increased life expectancy, contraceptive use, labor market participation, economic uncertainty and value changes were the main reasons for delayed childbearing [11-13]. On the contrary, some studies indicated that multiparous women continuing childbearing to advanced maternal age because of ignorance, low use of contraceptive methods, and remarriage $[14,15]$. The socio-economic and technological changes have significantly contributed to increasing the number of women who delay childbearing. This demographic shift speculated as a public health issue, and it becomes challenging for both patients and clinicians. Delaying pregnancy too advanced age increased the risk of adverse perinatal outcomes [4, 6, 10, 16-19].

Women with AMA revealed a significantly increased risk of prematurity and unfavorable perinatal outcomes [20]. Evidence from different studies indicated that AMA significantly increased the risk of prematurity, fetal mortality, early neonatal mortality, perinatal mortality, low birth weight, and birth asphyxia [1, 2, 5, 7-9, 2123]. A result of a study conducted in Nepal showed the older women had a significantly higher incidence of perinatal death (7.7\% vs. 0\%) [24]. Similarly, a study conducted in South Africa reported that older women had an increased risk of perinatal death as compared to the younger ones [25].

\section{Impact of advanced maternal age in Ethiopia}

Findings from Ethiopia revealed that AMA was increasingly associated with adverse perinatal outcomes like prematurity, low birth weight, perinatal death, stillbirth, and low fifth-minute Apgar score [26, 27].

\section{The rationale of the study}

Thus, studies on the effect of advanced maternal age on perinatal outcomes are very important for policymakers and program evaluators to improve perinatal health. Some studies conducted in different settings [1, 2, 5, 7-9, 21-23]. Nevertheless, most were conducted retrospectively and depend on charts or record reviews, which is more prone to biases. Besides, there are limited studies in-country Ethiopia as AMA steadily increasing. Therefore, this study aimed to assess the status of advanced maternal age and its effect on perinatal outcomes in the study setting.

\section{Hypothesis}

This study hypothesized that advanced maternal age increases the risk of adverse perinatal outcomes after controlling possible confounding variables.

\section{Methods}

Study setting and period

In this study, women's in Arba Minch zuria, and Gacho Baba district, Arba Minch-Health, and Demographic Surveillance System sites (AM-HDSS), southern Ethiopia involved, from October 15, 2018, to September 30, 2019. Arba Minch-Health and Demographic Surveillance System sites were established in collaboration between Arba Minch University and Ethiopian Public Health Association with the support of the Centers for Disease Control and Prevention (CDC) Ethiopia in 2009 to track demographic changes. The surveillance site included nine kebeles from the 29 kebeles located in Arba Minch zuria, and Gacho Baba district, Gamo zone, southern Ethiopia [28]. Arba Minch is an administrative town in the Gamo zone, located $505 \mathrm{~km}$ south of Addis Ababa and $275 \mathrm{~km}$ southwest of Hawassa. Based on the 2007 Census conducted by the Central Statistical Agency (CSA), these districts have a total population of 164,529 , of whom 82,199 are men and 82,330 women. According to the HDSS report, there is a total population of 74,157 in the surveillance site.

\section{Study design}

A community-based prospective cohort study design was employed to meet study objectives.

\section{Population}

\section{Source population}

The source population for this study was all women who were pregnant in Arba Minch zuria, and Gacho Baba district, AM-HDSS site, southern Ethiopia.

\section{Study population}

Those women who were pregnant during the study period (2018-2019) were study population for this study.

\section{Inclusion criteria}

At enrollment for this study, all women who were pregnant and inhabitants to a minimum of six months in the study area were eligible for this study. The eligibility defined by the pregnancy screening checklist, which was developed by Whiteman et al. [29]. 


\section{Exclusion criteria}

During recruitment, all women whose ages less than twenty years old and known to be preexisting illnesses excluded from the study.

\section{Sample size determination}

Epi info7 software Stat Calc used to estimate the sample sizes. For the first objective, a single population proportion was used by considering the following assumptions: $P=0.334$ from the study conducted in Norway [9], 95\% level of confidence, and 5\% margin of error used. Based on this, the estimated sample size was 342. A twosample comparison proportion used to estimate the sample size for the second objective. The assumption was $P_{1}$ (age group 20-34) $=0.207$ and $P_{2}$ (age group $\geq 35)=0.124$ in the study conducted in Malaysia [10], $95 \% \mathrm{CI}$, ratio $1: 1$, and Power $=80 \%$ and the sample size estimated by this assumption was 676 . The sample size for this study estimated by adding a non-response rate of $10 \%$ to the larger sample size. Therefore, the calculated sample size for this study was 744 .

\section{Data collection tool}

The data were collected using a pretested intervieweradministered structured Open Data Kit (ODK) survey tool. The tools were developed by reviewing different works of literature. The wealth index assessment questionnaire adapted from the questionnaire used in the Ethiopian Demographic Health Survey (EDHS) 2016 [30]. The household food insecurity level measured with Household Food Insecurity Access Scale (HFIAS), a structured, standardized, and validated tool that developed mainly by Food and Nutrition Technical Assistance (FANTA) [31]. They have three main parts for the questionnaire: Part I (pregnancy screening checklist), Part II (baseline information), and Part III (follow-up survey tool) (Additional file 1).

\section{Pretest}

The tools pretested in the Chencha district, which was out of the study area to verify the appropriateness, and modifications and amendments were taken accordingly before actual data collection.

\section{Data collection procedures}

The well-trained nine data collectors and three field supervisors were prospectively identified perinatal outcomes among pregnant women during the study period. Intensive three days training gave for data collectors and supervisors separately regarding objectives of the study and data collection ways. Data collectors discussed the information about the ODK survey tool and pregnancy screening checklists to identify pregnant women. The data collected in different phases, as this was a community-based prospective follow-up study. In the first phase: all the baseline information about the women obtained and pregnancy status was checked by using a pregnancy-screening checklist. After identified whether women were advanced age or not, and the data collectors have recruited the women into the cohort. In the second phase: the women were followed started from the time pregnancy confirmed up to the immediate postpartum period to identify some of the perinatal outcomes. The follow-up terminated at the end of the neonatal period that the neonates reassessed with a similar fashion in the above mechanism. In the community setting, the data collectors frequently contacted women or any household members, surround health care institutions, and health extension workers during the followup period.

\section{Study variables and measurements}

The description and measurements for some of the outcome and explanatory variables were stated in detail below (Table 1).

\section{Data quality assurance}

To ensure quality, experts translated questionnaires into the local language. A standard tool, which was commented by many experts, was used to collect the information. The data collectors and supervisors trained to standardize and ensure consistency of data collection. The principal investigator and supervisors critically checked the data for completeness before uploaded to the ODK cloud server. Multiple imputation techniques used for the missed data that were not more than $20 \%$ of the needed information. The inconsistent data excluded from the final analysis. The data coded correctly and categorized to maintain quality.

\section{Data processing and analysis}

The collected data were downloaded from ODK aggregate and exported to SPSS version 25 for analysis. Proportions and summary statistics computed with maternal age. The wealth quintiles determined by the Principal Component Analysis (PCA). A crude and adjusted log-linear regression analysis was done for each outcome variable with maternal age to estimate the beta coefficient $(\beta)$. The assumptions for log-linear regression checked, and the log-likelihood ratio tested for the goodness of fit. To control the confounding effect, all the variables with $P \leq 0.25$ in the bivariate analysis included in the final model. The model adjusted for educational and occupational status, parity, wealth index, body mass index (BMI), HFIAS, lifestyle factors, distance to health care institution, and sex of the neonate, antenatal care, postnatal care, and place of delivery. A standard error of $>2$ considered as suggestive of the existence of multi co- 
Table 1 Measurements to assess the status of advanced maternal age and their effect on perinatal outcomes in Arba Minch zuria, and Gacho Baba district, southern Ethiopia, 2018/9

\begin{tabular}{|c|c|c|}
\hline Variables & Description & Measurements \\
\hline \multicolumn{3}{|l|}{ Perinatal outcomes } \\
\hline Gestational age & $\begin{array}{l}\text { A period counted from the Last Normal Menstrual } \\
\text { Period (LNMP) if the mother remembered, or } \\
\text { based on Ultrasound result during pregnancy. }\end{array}$ & $\begin{array}{l}\text { Neonate's gestational age categorized as pre-term for } \\
\text { less than } 37 \text { weeks coded as "1", a term for } 37-42 \text { weeks } \\
\text { coded as " } 2 \text { ", and post-term } 42+\text { weeks coded as "3". }\end{array}$ \\
\hline Size of the neonate & $\begin{array}{l}\text { Birth weight or size of the neonate during } \\
\text { delivery. }\end{array}$ & $\begin{array}{l}\text { The size of the neonate categorized as very small } \\
\text { coded as " } 1 \text { ", smaller than usual coded as " } 2 \text { ", about } \\
\text { average coded as " } 3 \text { ", and larger than usual coded } \\
\text { as " } 4 \text { ". }\end{array}$ \\
\hline Stillbirth & $\begin{array}{l}\text { Give birth to a dead fetus after } 28 \text { weeks of } \\
\text { gestation. }\end{array}$ & $\begin{array}{l}\text { Those conceptuses ended up with stillbirth coded } \\
\text { as " } 1 \text { ", and the other coded as "2". }\end{array}$ \\
\hline Neonatal mortality & Neonates died within 28 days of birth. & $\begin{array}{l}\text { Those neonates died within } 28 \text { days by the } \\
\text { non-accident case were coded as "1", not were } \\
\text { coded as " } 2 \text { ". }\end{array}$ \\
\hline \multicolumn{3}{|l|}{ Exposure variable } \\
\hline Advanced maternal age & $\begin{array}{l}\text { Defined as a pregnant mother aged } \geq 35 \text { years } \\
\text { old [17]. }\end{array}$ & $\begin{array}{l}\text { Categorized into two groups, and for the mother } \\
\text { aged } 20 \text { - } 34 \text { years old was coded as " } 1 \text { " and " } 2 \text { " } \\
\text { for } \geq 35 \text { years. }\end{array}$ \\
\hline \multicolumn{3}{|c|}{ Adjusted/confounding and some other variables } \\
\hline Parity & Number of births that the woman have & $\begin{array}{l}\text { The responses categorized into two categories as } \\
\text { primi ( } 1 \text { st birth order) coded as " } 1 \text { " and multipara } \\
\text { ( } 2 \text { or more birth order coded as " } 2 \text { ". }\end{array}$ \\
\hline$B M l$ & Weight of women in $\mathrm{kg}$ per height square & $\begin{array}{l}\text { Classified into underweight } \\
(<18.5 \mathrm{~kg} / \mathrm{m} 2) \text {, normal }(18.5-24.9 \mathrm{~kg} / \mathrm{m} 2) \text {, } \\
\text { overweight }(25-29.9 \mathrm{~kg} / \mathrm{m} 2), \text { obese }(30-34.9 \mathrm{~kg} / \mathrm{m} 2) \text {, } \\
\text { and morbidly obese }(\geq 35 \mathrm{~kg} / \mathrm{m} 2)\end{array}$ \\
\hline Wealth index & $\begin{array}{l}\text { The EDHS household assets questions used, } \\
\text { and principal component analysis done to } \\
\text { rank the categories. }\end{array}$ & $\begin{array}{l}\text { It ranked into three categories, } 1 \text { st quantile coded } \\
\text { as } 1,2 \text { nd quantile coded as " } 2 \text { ", and 3rd quantile } \\
\text { coded as " } 3 \text { ". }\end{array}$ \\
\hline Distance to the health center & $\begin{array}{l}\text { Approximate distance to the health center } \\
\text { on foot which was responded by the } \\
\text { respondent }\end{array}$ & $\begin{array}{l}\text { Categorized in to two: "1" }=\leq 2 \mathrm{~h} \text { on foot and } \\
" 2 "=>2 \mathrm{~h}(\mathrm{BEmOC})\end{array}$ \\
\hline Distance to the hospital & $\begin{array}{l}\text { Approximate distance to the hospital on foot } \\
\text { which was responded by the respondent }\end{array}$ & $\begin{array}{l}\text { Categorized in to two: "1" }=\leq 2 \mathrm{~h} \text { on foot and } \\
" 2 "=>2 \mathrm{~h}(\text { CEmOC) }\end{array}$ \\
\hline Household food insecurity & $\begin{array}{l}\text { Both physical and economic access to } \\
\text { sufficient food to meet their dietary needs } \\
\text { for a productive and healthy life }\end{array}$ & $\begin{array}{l}\text { Categorized households into four levels of } \\
\text { household food insecurity (access) based on } \\
\text { response to nine questions of HFIAS: food secure } \\
\text { (1) and mild (2), moderately (3), and severely food } \\
\text { insecure (4) [31]. }\end{array}$ \\
\hline Districts (woreda) & \multicolumn{2}{|l|}{$\begin{array}{l}\text { It is the third-level administrative divisions } \\
\text { of Ethiopia. }\end{array}$} \\
\hline Kebele (wards) & \multicolumn{2}{|c|}{$\begin{array}{l}\text { Defined as the smallest administrative unit of Ethiopia, and it is a neighborhood or a localized and delimited group } \\
\text { of people. }\end{array}$} \\
\hline
\end{tabular}

linearity. In this study, $P<0.05$, considered to declare a result as a statistically significant association. Then the information, presented in simple frequencies, summary measures, tables, and figures.

\section{Results}

In this follow-up study, 744 women's interviewed in the baseline based on the calculated sample size, and 709 completed the follow-up period, which gave the response rate of $95.3 \%$ (Fig. 1).

\section{Socio-demographic and economic characteristics with maternal age}

Out of study participants, $500(70.5 \%)$ were age ranged from 20 to 34 years old, and 209(29.5\%) were $\geq 35$ years old. From women whose age group 20-34 years old, 308(61.6) had no formal education, 143(28.6) had primary, 35(7.0) secondary, and 14(2.8) college and above, and for age group $\geq 35$ years old, 144(68.9) had no formal education, and 47(22.5), 13(6.2), and five (2.4) had primary, secondary, and college and above respectively. Four hundred ninety-six (99.2\%) of participants married 


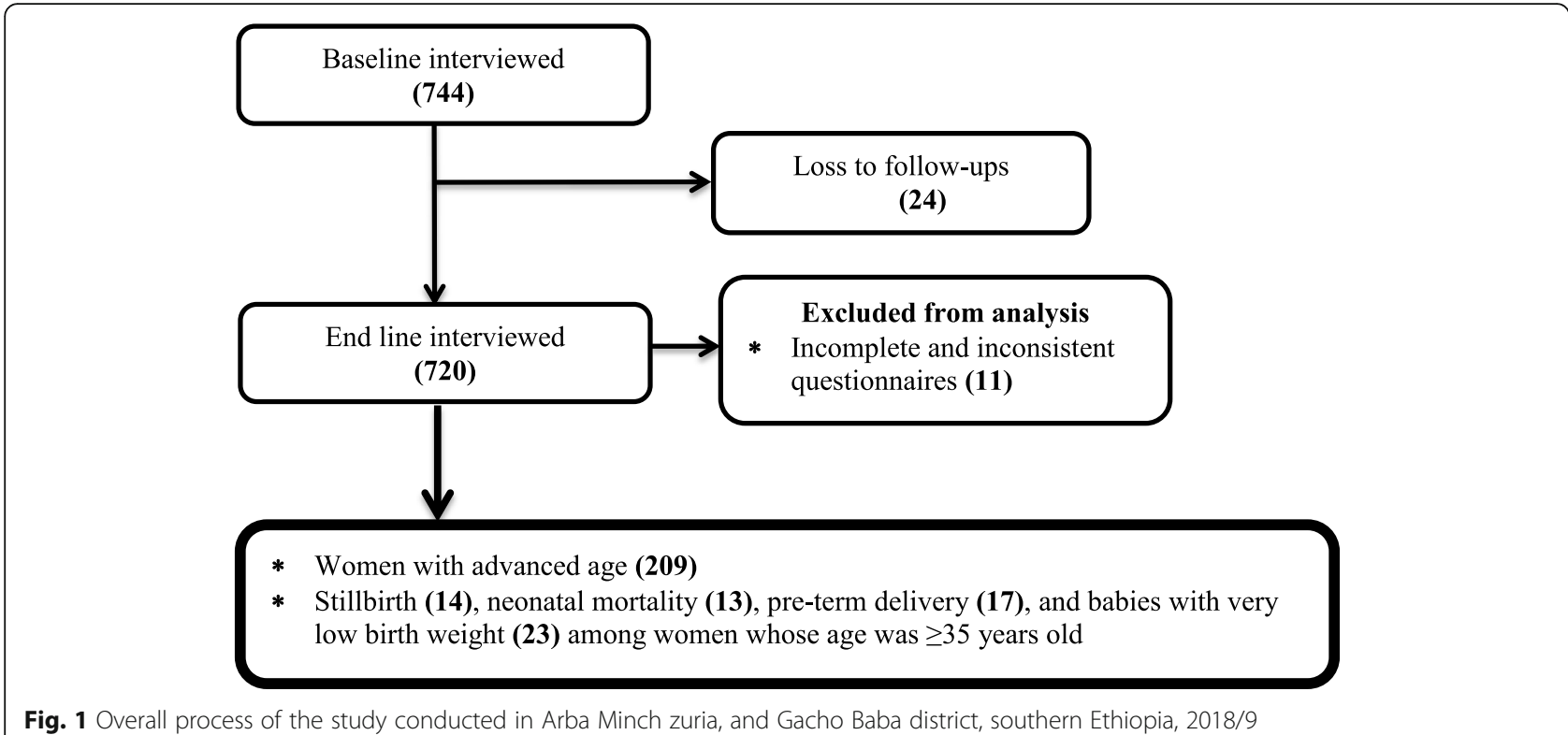

Fig. 1 Overall process of the study conducted in Arba Minch zuria, and Gacho Baba district, southern Ethiopia, 2018/9

for the age group 20-34 years and 208(99.5) for age $\geq 35$ years (Table 2).

Household food insecurity access scale with maternal age Of the women whose age was 20-34 years old, 325 $(65.0 \%)$ and $144(68.9 \%)$ whose age 35 years old or more were food secure (Fig. 2).

\section{Maternal characteristics with age}

Out of study participants, $88(17.6 \%)$ of study participants were primipara for age $20-34$ years, $16(7.7 \%)$ for $\geq 35$ years. Antenatal care was followed by $363(72.6 \%)$ of women age $20-34$ years and $151(72.2 \%)$ for 35 years or more (Table 3).

\section{Lifestyle factors of the women with age}

Regarding lifestyle factors of the women, 20(4.0\%) and 93 (18.6\%) had smoking and consumed alcoholcontaining beverages for the age group from 20 to 34 years, and $14(6.7 \%)$, and $40(19.1 \%)$ for age category 35 years old or more respectively. Thirty-two $(6.4 \%)$ of women with group $20-34$, and 11 (5.3\%) for age group $\geq 35$ years old used hashish/shisha/suret, and 36(7.2\%) of the women with group $20-34$, and $20(9.6 \%)$ for age group $\geq 35$ years old consumed local herbs.

\section{Perinatal characteristics with maternal age}

Of the neonates, $228(46.8 \%)$ were male for the women aged $20-34$ years, and $104(56.8 \%)$ for the age group $\geq 35$ years. Ten $(2.1 \%)$ of the neonates encountered complications during the period for the age group 20-34 years, and four $(2.2 \%)$ for women aged 35 years or more (Table 4).

\section{Association of maternal age with adverse perinatal outcomes}

The adjusted model showed a significant association between maternal age and neonatal mortality and stillbirth. Women with age group $\geq 35$ years old had significantly increased the risk of neonatal mortality and stillbirth as compared to the age group ranged from 20 to 34 years ( $\beta=0.11$; $95 \%$ CI: $0.01,0.21)$, and $(\beta=0.29$; $95 \%$ CI: 0.05 , $0.52)$ respectively (Table 5 ).

\section{Discussion}

This prospective cohort study aimed to fill research gaps in Ethiopia in assessing the status of advanced maternal age and their effect on the perinatal outcomes. In this finding, 1/3rd of women became pregnant during advanced maternal age. This study reported the association of advanced maternal age to adverse perinatal outcomes, such as stillbirth and neonatal mortality.

In this study, the status of AMA was $29.5 \%(95 \% \mathrm{CI}$ : $26.1,32.8 \%)$. This was higher than studies conducted in Israel (2.3 and 14\%) [4, 8], Malaysia (14.8\%) [10], WHO Multicountry Survey (12.8\%) [7], Northeastern Brazil (5.9\%) [32], Nepal (4.53\%) [24], South Africa (17.5\%) [25], and United Kingdom (18.18\%) [33]. However, it was lower than studies done in Iran (50.2\%) [12], and Norway (33.4\%) [9]. This discrepancy may be due to differences in socio-demographic and economic characteristics, technological and health care systems, and socio- 
Table 2 Socio-demographic and economic characteristics with maternal age for the study conducted in Arba Minch zuria, and Gacho Baba district, southern Ethiopia, 2018/9

\begin{tabular}{|c|c|c|}
\hline Variables & $20-34$ years & $\geq 35$ years \\
\hline \multicolumn{3}{|c|}{ Educational status of the husband } \\
\hline No formal education & $254(50.8)$ & $110(52.6)$ \\
\hline Primary(1-8) & $171(34.2)$ & $76(36.4)$ \\
\hline Secondary(9-12) & $58(11.6)$ & $16(7.7)$ \\
\hline College and above & $17(3.4)$ & $7(3.3)$ \\
\hline \multicolumn{3}{|c|}{ Occupation of the mother } \\
\hline Housewife & $452(90.4)$ & $194(92.8)$ \\
\hline Other@ & $48(9.6)$ & $15(7.2)$ \\
\hline \multicolumn{3}{|c|}{ Occupation of the husband } \\
\hline Farmer & $358(71.6)$ & $178(85.2)$ \\
\hline Other \pm & $142(28.4)$ & $31(14.8)$ \\
\hline \multicolumn{3}{|l|}{ BMI (kg/m2) } \\
\hline Underweight $(<18.5)$ & $35(7.0)$ & $15(7.1)$ \\
\hline Normal (18.5-24.9) & $374(74.8)$ & $132(63.2)$ \\
\hline Overweight (25-29.9) & $91(18.2)$ & $62(29.7)$ \\
\hline \multicolumn{3}{|c|}{ The average distance from the health post (on foot) } \\
\hline$\leq 2 \mathrm{~h}$ & $485(97.0)$ & $206(98.6)$ \\
\hline$>2 \mathrm{~h}$ & $15(3.0)$ & $3(1.4)$ \\
\hline \multicolumn{3}{|c|}{ The average distance from the health center (on foot) } \\
\hline$\leq 2 \mathrm{~h}$ & $457(91.4)$ & $193(92.3)$ \\
\hline$>2 \mathrm{~h}$ & $43(8.6)$ & $16(7.7)$ \\
\hline \multicolumn{3}{|c|}{ The average distance from the hospital (on foot) } \\
\hline$\leq 2 \mathrm{~h}$ & $131(26.2)$ & $87(41.6)$ \\
\hline$>2 \mathrm{~h}$ & $369(73.8)$ & $122(58.4)$ \\
\hline \multicolumn{3}{|l|}{ Wealth index } \\
\hline First quantile & $178(35.6)$ & $59(28.2)$ \\
\hline Second quantile & $171(34.2)$ & $76(36.4)$ \\
\hline Third quantile & $151(30.2)$ & $74(35.4)$ \\
\hline
\end{tabular}

( ) merchant, government employer, daily laborer, student, and farmer, \pm carpenters, Manson, merchant, government employer, daily laborer, private worker, religious leader, student, and driver, and BMI: Body mass index cultural factors that lead to delayed childbearing or having pregnant at an advanced age. Typically, as this study conducted in a low-income country that women continue childbearing due to a shortage of contraceptive means and lack of knowledge on how to utilize it.

Finding from this study indicated that the risk of stillbirth significantly increased in AMA. These were congruent with studies conducted in the United Kingdom [33], Washington, United States [34], and in Ethiopia $[26,27]$. Correspondingly, neonatal mortality was also associated with AMA in this study. These were in line with studies conducted in Israel [4], South Australia [35], Scotland [36], Brazil [37], and Washington, United States [34]. The reason is that those old blood vessels in the uterus cause uteroplacental insufficiency. In advanced maternal age, the physical ability to bear the child in advanced maternal age may result in adverse perinatal outcomes such as stillbirth. Besides, as maternal age advances high likely give birth to a baby with different complications which unable to adapt extrauterine life and increased risk or more susceptible to infections.

After controlling for confounders, prematurity and post-term delivery were not significantly associated with AMA. This not in line with studies conducted in the United Kingdom [33], South Australia [35], Brazil [16], South Korea [18], Israel [19], and Ethiopia [26]. In this study, the estimated birth weight of babies was not significantly associated with AMA. These contradicted with the studies conducted in Brazil [16] and South Korea [18]. The reason for the discrepancy may be the methodological aspects (source population, sampling, and study participant characteristics) and socio-economic status.

The finding of this study is input for public health. In advanced maternal age, the risk of adverse perinatal outcomes increased significantly. Due to advanced health care delivery systems and technology and socio-

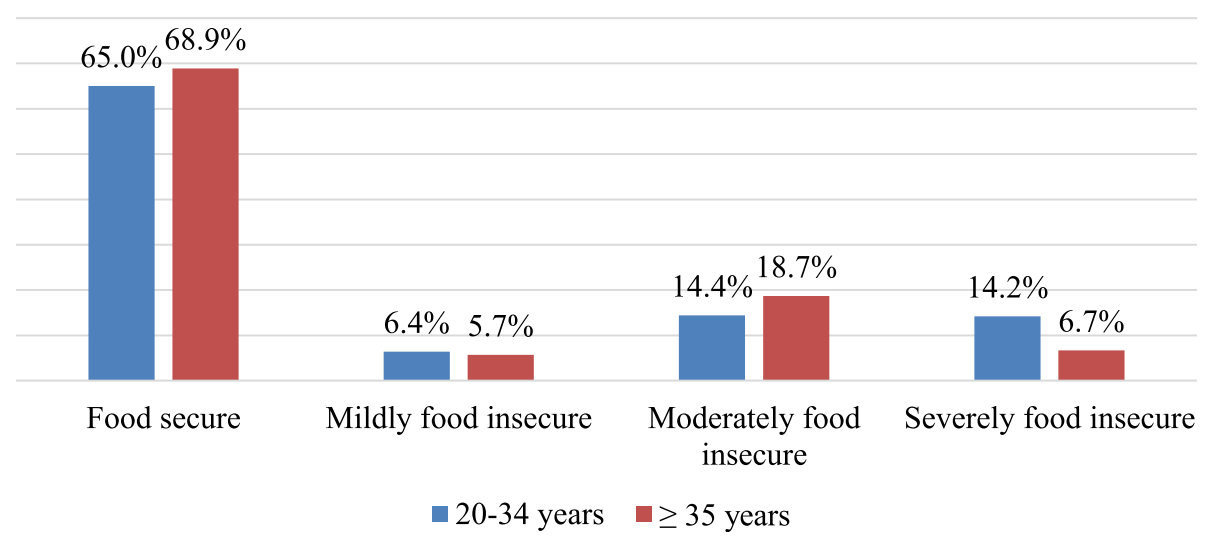

Fig. 2 Household food insecurity access scale with maternal age for the study conducted in Arba Minc Zuria, Gacho Baba District, AM-HDSS site, Southern Ethiopia, 2018/9 
Table 3 Maternal characteristics with age for the study conducted in Arba Minch zuria, and Gacho Baba district, southern Ethiopia, 2018/9

\begin{tabular}{lll}
\hline Variables & $\mathbf{2 0 - 3 4}$ years & $\mathbf{2 3 5}$ years \\
\hline ANC visits & $137(27.4)$ & $58(27.8)$ \\
No visit & $151(30.2)$ & $70(33.5)$ \\
$1-3$ visits & $212(42.4)$ & $81(38.8)$ \\
Four or more visits & & $16(8.7)$ \\
Place of delivery & $32(6.6)$ & $32(17.5)$ \\
Hospital & $145(29.8)$ & $19(10.4)$ \\
Health center & $69(14.2)$ & $116(63.4)$ \\
Health post & $241(49.4)$ & $169(92.4)$ \\
Home & & $7(3.8)$ \\
Mode of delivery & $429(88.1)$ & $7(3.8)$ \\
Spontaneous vaginally & $18(3.7)$ & $34(18.6)$ \\
Cesarean section & $40(8.2)$ & $149(81.4)$ \\
Assisted delivery & & \\
Postnatal care & $112(23.0)$ & \\
Yes & $375(77.0)$ & \\
No & &
\end{tabular}

ANC Antenatal care

Table 4 Perinatal characteristics with maternal age for the study conducted in Arba Minch zuria, and Gacho Baba district, southern Ethiopia, 2018/9

\begin{tabular}{lll}
\hline Variables & $\mathbf{2 0 - 3 4}$ years & $\geq \mathbf{3 5}$ years \\
\hline Stillbirth & $11(2.2)$ & $14(7.1)$ \\
Yes & $487(97.8)$ & $183(92.9)$ \\
No & & \\
Gestational age & $418(85.8)$ & $152(83.1)$ \\
Estimated at term & $21(4.3)$ & $17(9.3)$ \\
Estimated pre-term & $48(9.9)$ & $14(7.6)$ \\
Estimated post-term & & $23(12.6)$ \\
Size of the neonate & $79(16.2)$ & $11(6.0)$ \\
Very small & $46(9.4)$ & $140(76.5)$ \\
Smaller than usual & $328(67.4)$ & $9(4.9)$ \\
About average & $34(7.0)$ & $2(1.1)$ \\
Larger than usual & $181(98.9)$ \\
The baby referred to another facility & $13(7.1)$ \\
Yes & $5(1.0)$ & $170(92.9)$ \\
No & $482(99.0)$ & $182(99.5)$ \\
Admitted to NICU & & \\
Yes & $7(1.4)$ & $480(98.6)$ \\
No & & \\
Neonatal mortality & $11(2.3)$ & \\
Yes & $476(97.7)$ & \\
\hline & &
\end{tabular}

NICU Neonatal intensive care unit
Table 5 Association of maternal age to adverse perinatal outcomes for the study conducted in Arba Minch zuria, and Gacho Baba district, southern Ethiopia, 2018/9

\begin{tabular}{lll}
\hline $\begin{array}{l}\text { Perinatal } \\
\text { outcomes }\end{array}$ & \multicolumn{2}{l}{ Maternal age $\geq \mathbf{3 5}$ years } \\
\cline { 2 - 3 } & Crude estimate $\boldsymbol{\beta}$ & Adjusted estimate $\pm \boldsymbol{\beta}$ \\
\hline Stillbirth & $0.30(0.10,0.50)$ & $0.29(0.05,0.52)^{*}$ \\
Pre-term & $0.30(0.07,0.54)$ & $0.11(-0.07,0.28)$ \\
Post-term & $-0.20(-0.42,0.02)$ & $-0.01(-0.19,0.14)$ \\
Estimated small & $-0.02(-0.23,0.19)$ & $0.002(-0.04,0.04)$ \\
Estimated smaller & $-0.10(-0.37,0.16)$ & $0.007(-0.03,0.05)$ \\
than usual & & \\
Estimated larger & $-0.05(-0.34,0.24)$ & $0.007(-0.03,0.05)$ \\
than usual & & $0.11(0.01,0.21)^{*}$ \\
Neonatal mortality & $0.29(0.09,0.49)$ & .
\end{tabular}

tadjusted for educational status, occupational status, parity, wealth index, BMI HFIAS, lifestyle factors, distance to health care institutions, sex of the neonate, antenatal care, postnatal care, and place of delivery and *significant at $P<0.05$

economic status, the number of women who delayed childbearing increased from time to time. As such, studies on the effect of advanced maternal age on the adverse perinatal outcomes are vital to strengthen the intervention for women who planned to bear a child. The finding of this study initiates different stakeholders in the health care system to design appropriate strategies and planning for intervention. This study becomes one input for health policymakers and program developers typical regarding perinatal health.

The limitations of this were; some of the medical words were difficult to translate to the local language exactly. Some values are difficult to set cut off points, and based on the maternal response as subjected to social desirability bias. The main strength of this study that the design was a community-based prospective follow up that gave a relatively good measure of the effect of advanced maternal age on adverse perinatal outcomes. Standard and validated tools used to measure the pregnancy status, baseline assessment to maintain validity and reliability.

In summary, this study intended to fill a research gap in Ethiopia that shows the association of advanced maternal age on perinatal outcomes after controlling possible confounders. Stillbirth and neonatal mortality were significantly associated with advanced maternal age. Nevertheless, pre-term, post-term delivery, and estimated birth weight did not show a significate association. Even if the study design was prospective, the readers should consider the limitations of these other methodological aspects while interpreting the finding, and the other scholars would do more to overcome those limitations. The study will input for policymakers and different stakeholders to design appropriate strategies and planning for interventions. 


\section{Conclusions}

This study showed that a significant number of women became pregnant during advanced maternal age. Those adverse perinatal outcomes are unpredictable and unpreventable in the majority of bases. But, highly increased as women age advances. This study identified that stillbirth and neonatal mortality was significantly associated with advanced maternal age. As such, different intervention programs should design to create awareness and to provide counseling services for women with advanced age or delayed childbearing.

\section{Supplementary information}

Supplementary information accompanies this paper at https://doi.org/10 1186/s12884-020-03285-0.

Additional file 1. Tools

\section{Abbreviations}

AM-HDSS: Arba Minch-Health and Demographic Surveillance System sites; BMI: Body Mass Index; HFIAS: Household Food Insecurity Access Scale; ODK: Open Data Kit

\section{Acknowledgments}

Our unreserved thank goes to the Arba Minch zuria, and Gacho Baba district local administrators, kebele leaders, and health extension workers who gave support during data collection, data collectors, and study participants. Finally, yet importantly, I would like to say thank you for all peoples who support directly or indirectly.

\section{Authors' contributions}

AM designed the study, involved in data collection, done analysis and interpretation of the result and drafted the paper, and participated in preparing all versions of the manuscript. GA, TW, ZZ, SS, AB, and TC assisted in the design and the proposal development, monitored data collection, assisted during analysis, and revised subsequent drafts of the paper. All authors read and approved the final manuscript.

\section{Funding}

Arba Minch University provided funds for this research project with a grant code of GOV/AMU/TH/CMHS/NUR/DSS/04/10. The website of the university is www.amu.edu.et. "The funders had no role in study design, data collection, and analysis, decision to publish, or preparation of the manuscript."

\section{Availability of data and materials}

The datasets generated and/or analyzed during the current study are not publicly available due to anonymity issue but are available from the corresponding author on reasonable request.

\section{Ethics approval and consent to participate}

The Institutional Research Ethics Review Board (IRB) of the College of Medicine and Health Sciences, Arba Minch University, provided ethical clearance. Written and signed voluntary consent obtained from all study participants before recruiting the women of the neonate into the study. The anonymity of the participants respected via the use of codes. The respondents also informed that the information obtained from them treated with the utmost confidentiality.

\section{Consent for publication}

Not applicable.

\section{Competing interests}

All authors assert that they have no competing interests.

\section{Author details}

${ }^{1}$ School of Nursing, College of Medicine and Health Sciences, Arba Minch University, Arba Minch, Ethiopia. ${ }^{2}$ School of Public Health, College of Medicine and Health Sciences, Arba Minch University, Arba Minch, Ethiopia. ${ }^{3}$ Department of Medical Laboratory Sciences, College of Medicine and Health Sciences, Arba Minch University, Arba Minch, Ethiopia.

Received: 8 April 2020 Accepted: 25 September 2020

Published online: 06 October 2020

\section{References}

1. Aaserud K. Advanced maternal age: What you need to know about getting pregnant after 35. 2017. Available at: https://www.todaysparent.com/ pregnancy/being-pregnant/advanced-maternal-age-what-you-need-toknow-about-getting-pregnant-after-35/. Access date: [Feb 16, 2018].

2. Stowers P. Advanced Maternal Age-Risks and Precautions, 2014. Available at: https://www.everydayfamily.com/advanced-maternal-age-risks-andprecautions/. Access date: [Feb 16, 2018].

3. Dekker R, Niles M, Breakey A. Evidence on: Advanced Maternal Age, or Pregnancy at Age 35 or Older, 2016. Available at: https://evidencebasedbirth. com/advanced-maternal-age/. Access date: [Mar 5, 2018].

4. Yaniv S, Levy A, Wiznitzer A, Holcberg G, Mazor M, Sheiner E. A significant linear association exists between advanced maternal age and adverse perinatal outcome. Arch Gynecol Obstet. 2011;283:755-9.

5. Bekdas M, Demircioglu F, Kad Z, Kısmet E. Pregnancy outcome in women of advanced maternal age: a cross-sectional study in a Turkish maternity hospital. Maced J Med Sci. 2013;4(6):365-9.

6. Claramonte NM, Dominguez GC, Gich SI, Olivella GA, Parra RJ, Armengol SJ. Hospital de Sant Pau, Barcelona, Spain. Pregnancy and neonatal outcomes at advanced maternal age: prospective results from a tertiary university referral hospital in Barcelona, Spain. 2016. 15th World Congress in Fetal Medicine. Available at: https://fetalmedicine.org/abstracts/2016/var/pdf/ abstracts/01686.pdf. Accessed 16 Feb 2018.

7. Laopaiboon M, Lumbiganon P, Intarut N, Mori R, Ganchimeg T, Vogel JP, Souza JP, Gulmezoglu AM, on behalf of the WHO multicountry survey on maternal newborn Health Research network. Advanced maternal age and pregnancy outcomes: a multicountry assessment. BJOG. 2014;121(Suppl. 1): 49-56.

8. Schimmel MS, Bromiker R, Hammerman C, Chertman $L$, et al. The effects of maternal age and parity on maternal and neonatal outcome. Arch Gynecol Obstet. 2015;291:793-8.

9. Wang $Y$, Tanbo T, Abyholm T, Henriksen T. The impact of advanced maternal age and parity on obstetric and perinatal outcomes in singleton gestations. Arch Gynecol Obstet. 2011;284:31-7.

10. Rashed HE, Awaluddin SM, Ahmad NA, Supar NH, Lani Z, Aziz F, et al. Advanced maternal age and adverse pregnancy outcomes in Muar, Johor, Malaysia. Sains Malaysiana. 2016;10(45):1537-42.

11. Mills M, Rindfuss RR, McDonald P, te Velde E. Why do people postpone parenthood? Reasons and social policy incentives. Hum Reprod Update. 2011;17(6):848-60

12. Yazdani M, Amirshahi E, Shakeri A, Amirshahi R, Malekmakan L. Prenatal, and maternal outcomes in advanced maternal age, a comparative study. Women's Health Bull. 2015;2(2):e23092.

13. Solanke BL, Salau OR, Popoola OE, Adebiyi MO, Ajao OO. Sociodemographic factors associated with delayed childbearing in Nigeria. BMC Res Notes. 2019;12(1):374. Published 2019 Jul 1. https://doi.org/10.1186/ s13104-019-4414-X.

14. Obed SA, Armah JO, Wilson JB. Advanced maternal age and pregnancy. West Afr J Med. 1995;14(4):198-201. PMID: 8634223.

15. Guedes M, Canavarro MC. Characteristics of Primiparous women of advanced age and their partners: a homogenous or Heterogenous group? Birth. 2014;41(1):46-55.

16. Almeida NK, Almeida RM, Pedreira CE. Adverse perinatal outcomes for advanced maternal age: a cross-sectional study of Brazilian births. J Pediatr (Rio J). 2015;91:493-8

17. Walker KF, Thornton JG. Advanced maternal age. Obstetrics Gynaecol Reprod Med. 2016;26(12):335-57.

18. Yu-Jin K, Hyun-Mee R, Jae-Hyug Y, Ji-Hyae L, Ji-Eun L, Moon-Young K, JinHoon C. Pregnancy outcomes according to increasing maternal age. Taiwanese J Obstetrics Gynecol. 2012;51:60-5. 
19. Yogev Y, Melamed N, Bardin R, Tenenbaum-Gavish K, Ben-Shitrit G, Avi B-H. Pregnancy outcome at extremely advanced maternal age. Am J Obstet Gynecol. 2010;203:558.

20. Blomberg M, Birch Tyrberg R, Kjølhede P. Impact of maternal age on obstetric and neonatal outcome with emphasis on primiparous adolescents and older women: a Swedish medical birth register study. BMJ Open. 2014; 4:e005840. https://doi.org/10.1136/bmjopen-2014-005840.

21. Gluck O, Mizrachi Y, Bar J, Barda G. The impact of advanced maternal age on the outcome of twin pregnancies. Arch Gynecol Obstet. 2018;297(4): $891-5$.

22. Ngowa JD, Ngassam AN, Dohbit JS, Nzedjom C, Kasia JM. Pregnancy outcome at advanced maternal age in a group of African women in two teaching Hospitals in Yaounde, Cameroon. Pan Afr Med J. 2013;14:134.

23. Khalii A, Syngelaki A, Maiz N, Zinevich Y, Nicolaides K. Maternal age and adverse pregnancy outcome: a cohort study. Ultrasound Obstet Gynecol. 2013;42:634-43.

24. Giri A, Srivastav VR, Suwal A, Tuladhar AS. Advanced maternal age and obstetric outcome. Nepal Med Coll J. 2012;15(2):87-90.

25. Hoque ME. Advanced maternal age and outcomes of pregnancy: a retrospective study from South Africa. Bio Med Res. 2012;23:281-5.

26. Mehari M, Maeruf H, Robles CC, Woldemariam S, Adhena T, et al. Advanced maternal age pregnancy and its adverse obstetrical and perinatal outcomes in Ayder comprehensive specialized hospital, northern Ethiopia, 2017: a comparative cross-sectional study. BMC Pregnancy Childbirth. 2020;20(1):60.

27. Berhe T, Gebreyesus H, Teklay H. Prevalence and determinants of stillbirth among women attended deliveries in Aksum general hospital: a facility based cross-sectional study. BMC Res Notes. 2019;12(1):368.

28. Gultie T, Ayele G, Tariku B, Kondale M, Zerdo Z, Merdekiyos B, Tsalla T, et al. Trend of declining bed net utilization among pregnant women in Ethiopia: new data from the Arba Minch health and demographic surveillance system, 2010-2016. Malar J. 2020;19(1):142.

29. Whiteman MK, Tepper NK, Kottke M, Curtis KM, Goedken P, MMandel IG Marchbanks PA. Using a checklist to assess pregnancy in teenagers and Young women. Obstet Gynecol. 2014;123(4):777-84.

30. EDHS, Central Statistical Agency (CSA) [Ethiopia] and ICF. Ethiopia Demographic and Health Survey 2016: Key Indicators Report. Addis Ababa, Ethiopia, and Rockville, Maryland, USA: CSA and ICF; 2016.

31. Coates J, Swindale A, Bilinsky P. Household food insecurity access scale (HFIAS) for measurement of household food access: Indicator guide (v. 3). Washington, D.C.: Food and Nutrition Technical Assistance Project, Academy for Educational Development; 2007.

32. Figuerêdo ED, Lamy FF, Lamy ZC, Silva AA. Maternal age and adverse perinatal outcomes in a birth cohort (BRISA) from a Northeastern Brazilian city. Rev Bras Ginecol Obstet. 2014.36(12):562-8.

33. Kenny LC, Lavender T, McNamee R, O'Neill SM, Mills T, et al. Advanced maternal age and adverse pregnancy outcome: evidence from a large contemporary cohort. PLoS One. 2013;8(2):e56583. https://doi.org/10.1371/ journal.pone.0056583.

34. Lisonkova S, Potts J, Muraca GM, Razaz N, Sabr Y, Chan W-S, et al. Maternal age and severe maternal morbidity: a population-based retrospective cohort study. PLoS Med. 2017;14(5):e1002307. https://doi.org/10.1371/ journal.pmed.1002307.

35. Ludford I, Scheil W, Tucker G, Grivell R. Pregnancy outcomes for nulliparous women of advanced maternal age in South Australia, 1998-2008. Aust N Z J Obstet Gynaecol. 2012;52:235-41.

36. Pasupathy D, Wood AM, Pell JP, Fleming M, Smith GC. Advanced maternal age and the risk of perinatal death due to intrapartum anoxia at term. J Epidemiol Community Health. 2011;65:241-5.

37. Fonseca SC, Flores PVG, Camargo JKR, Pinheiro RS, Coeli CM. Maternal education and age: inequalities in neonatal death. Rev Saude Publica. 2017; $51: 94$

\section{Publisher's Note}

Springer Nature remains neutral with regard to jurisdictional claims in published maps and institutional affiliations.

\section{Ready to submit your research? Choose BMC and benefit from:}

- fast, convenient online submission

- thorough peer review by experienced researchers in your field

- rapid publication on acceptance

- support for research data, including large and complex data types

- gold Open Access which fosters wider collaboration and increased citations

- maximum visibility for your research: over $100 \mathrm{M}$ website views per year

At BMC, research is always in progress.

Learn more biomedcentral.com/submissions 